\title{
GHASHĀM. ESCENA DRAMÁTICA DE LA OBRA LOS DICHOS DE ABDELKADER ALLOULA
}

NAIMA BENAICHA ZIANI

Universidad de Alicante

\section{NOTA INTRODUCTORIA}

La trilogía de Abdelkader Alloula gira en torno a personajes de la ciudad de Orán, personajes inspirados en trabajadores reales en los que, cualquiera que haya vivido algo parecido, se pueda sentir identificado. $Y$ es aquí donde reside la fuerza de la obra del difunto dramaturgo argelino. En efecto, la llamada «Trilogía» pertenece a un teatro que sigue el modelo de la balqa argelina $^{1}$, un teatro en el que el público se sitúa alrededor del actor, formando un círculo ( $h a l q a$ ) como parte del espectáculo. Entretanto, un actor cuenta una o varias historias entrelazadas, interpretando todos y cada uno de los personajes, alternando prosa y poesía, e intercalando canciones tomadas de la poesía popular.

Los dichos, una de las piezas de la trilogía de Alloula, se presenta como un conjunto de tres escenas independientes. Tres tomas de palabras insólitas, tres historias de tres vidas, todas ellas contadas con un tono de confidencialidad. Una confidencialidad que encontramos en cada una de sus escenas.

Incluye un empleado desafiando a la autoridad de su líder, quien instruirá a su propio juicio. Una niña, obligando a las convenciones y tabúes, entra en el mundo de los adultos y se apropia de sus palabras. Y la escena que aquí presentamos, llama-

1 "La Halqa est un théâtre complet!", Abdelkader Alloula, Horizons maghrébins, Horizons maghrébins, en Mohammed Habib Samrakandi, Le théâtre arabe au miroir de lui-même et son contact avec les créations des deux rives de la Méditerranée, Toulouse, Université de Toulouse-Le Mirail, 2008, núm. 58, pp. 12-20. 
da Ghashäm, la historia de un trabajador que, a sabiendas de su inminente muerte, decide contar a su hijo varón cómo transcurrió su vida. Una vida ocultada y no compartida, con un único fin, el de no compartir con la familia la desesperación.

\section{GHASHÄM}

Siéntate Mesaūd, hijo... siéntate.

¿Por dónde empiezo?

¿Está la puerta cerrada?

Bueno... Mesaūd, hijo mío, hoy eres todo un hombre, gracias a Dios...

Las palabras que tenía preparadas para decirte, me traicionaron... el asunto es difícil, puesto que es la primera vez que hablo contigo de tú a tú... de hombre a hombre...

Estoy como asustado... es la primera vez que vamos a pasar de: buenos días padre, buenas tardes hijo... estás cansado, padre... si...

Hijo, estoy como aterrado...

Mira, escucha a tu padre y piensa que tienes delante a un amigo o un hermano... 
Tengo el corazón lleno y me gustaría desahogarme...

Llevo tiempo deseando llegar a este momento...

Lo deseaba pero me lo imaginaba de otra forma...

Te pido que prestes atención a lo que te digo...

Me dejarás que hable, y no me cortes, y si me alejo del tema no me preguntes por qué...

Filtrarás mis palabras y te quedarás con lo que te sirve...

Ghashām, tu padre es, por desgracia, analfabeto...

Yo te voy diciendo y tú irás poniendo orden en lo que consideres, ¿estamos?...

A lo que íbamos... esta misma mañana me han cesado en el trabajo...

Soségate, no te preocupes, y déjame que te cuente...

Me cesaron, y no hubo ni protesta ni malas caras...

Me cesaron con una sonrisa y consentí...

Llevan meses estudiándolo y por fin esta misma mañana decidieron... 
La doctora de la empresa me entregó, esta mañana, un papel y me dijo:

Desde la dirección, hemos estudiado su caso y hemos decidido pedirle que deje de trabajar definitivamente... padece usted una enfermedad del pumón, y no puede seguir trabajando...

Ha de tratarla, puesto que su enfermedad es bastante peligrosa...

¿Cómo de peligrosa, hija?

No tiene cura...

¿Cómo que no se cura?

Su pulmón está muy tocado, invadido por la enfermedad...

Me nombró la enfermedad, pero no la recuerdo; estaba aturdido, y bañado en un sudor repentino.

He suspirado, y en un suspiro vi cómo mi vida entera desfilaba ante mí...

Todo me vino en este momento: los momentos de pena, la fiebre, el hambre, el frío, las inquietudes, la desesperación, las luchas, las injusticias, en fin, todo lo que he vivido... 
¿Los pulmones tocados? ¿Y esto no tiene cura, hija?

Me dijo: sí, tiene remedio para aliviar el dolor y la tos, pero no tiene cura alguna...

Me flaquearon las rodillas, me apoyé contra la pared, y me dejé caer sobre un banco...

Ghashām, tu pobre padre estaba aterrado,

Me temblaban las manos, doblé el papel que me dio, lo guardé y me quedé con las manos dentro de los bolsillos...

Me dije a mi mismo: "sé un hombre, ármate de hombría

Ghashām, hijo, la muerte es inevitable”...

La doctora sacó un expediente, se puso a rellenarlo preguntándome: cinco hijos... Zeineb, Mesaūd, Ahmed, Zulija y Meriem... sólo Zeineb está casada... ¿ ¿tenía usted cuarenta y ocho años cuando empezó a trabajar en esta empresa?

SÍ... y ahora tiene cincuenta y nueve...

Sí... cuando empezó en esta empresa ¿no le hicieron un reconocimiento, una radiografía?...

NO... ¿por qué?... 
Su enfermedad es vieja...

¿Cómo de antigua?

Sí, antigua... cogió la enfermedad por causa del polvo, antes de empezar a trabajar aquí... y aquí se acentuó...

¿Trabajó usted cuatro años en la Carièrre? Sí, un año en la vidriera y ocho en la mina.

¿En la mina trabajó en la superficie o abajo?

En el fondo...

¿Y qué hacía en la vidriería? ¿Qué hacía exactamente?

Ayudaba a los que trabajaban y decoraban los cristales cargándoles arena...

Su salario se verá afectado con una bajada y lo percibirá de la seguridad social...

Eso quiere decir...

No, esto es mejor que la jubilación...

¿Y lo dejo hoy mismo?... 
Sí, hoy mismo... llévese este papel y hable con el responsable de su taller, que le acompañe a la dirección, para que le paguen y que le entreguen toda la documentación necesaria... mañana, cuando acabe con el papeleo, venga a llevarse los medicamentos...

Y después ¿qué?

Después vendrá una vez al mes para un reconocimiento...

Dígame, ¿̇me está diciendo que cogí la enfermedad por respirar polvo?...

$\mathrm{Si}$, del polvo fino que respiraba cuando trabajaba en el carbón y la arena... aquel polvillo llegó a penetrar en sus pulmones, se aglutinó, amasó y le dañó los pulmones...

No supe qué decirle, y me puse a respirar e inspirar como un animal agotado...

Pobre doctora, me miraba fijamente con los ojos húmedos y me dijo:

"de todas formas, Don Ghashām, aquí estamos para lo que haga falta y para aliviarle el dolor... 
Que Dios te proteja, hija...

Me apretó la congoja y no supe qué decirle... le dije que Don Ghashām se ha hecho mayor... trabajó y cumplió con su deber, y ahora toca aceptar el destino... buena gente la pobre, le vi cómo le afectaba todo aquello y cómo intentó ocultarlo... le di la espalda agradeciéndole su gesto, me despedí de ella y salí perdido... me puse a caminar, hijo mío, con la razón ausente, caminaba pensando en ti, en tu hermano Ahmed, tus hermanas Zulija y Meriem y en tu madre Badra...

Badra, vuestra madre, la hija de El-'Arbi...

Caminaba con las palabras de la doctora retumbando en mi cabeza, como una tormenta de polvo... Ghashām, hijo de Daūd, se apagaba poco a poco...

En fin, volví a la fábrica y lo peor aún quedaba por venir; cuando llegué al taller donde trabajo... todos mis compañeros lo sabían. Apenados, intentaban ocultarlo...

No cabe ni la menor duda de que Bu'alem, el liberado sindical les informaría y les daría las recomendaciones necesarias: de cómo tratarme y de cómo me hablarían para aliviar mi dolor... 
Me fui directo a recoger mis pertenencias, y quitando el saludo y la sonrisa nadie me dirigió la palabra...

Me entró un escalofrío, y sentí helarse mi corazón.

Vi en sus caras y su silencio la muerte cercana... cada vez que pasaba cerca de uno de ellos, se apresuraba en el trabajo como si el tiempo se le fuera a acabar, pero oía cómo decían para sus adentros:

"pobre Ghashām, desde que escupió sangre no ha vuelto a levantar cabeza"...

Pobre Ghashām, no se lo merece...

Continuaba caminando, cabizbajo, viendo cómo me seguían con la mirada...

Pobrecitos, qué susto se llevarían.

Todos temían contagiarse con la enfermedad... me puse a recoger mis cosas hasta que me interrumpió el encargado del taller, tomó el papel que llevaba en la mano y me dijo: "me adelanto a la administración”... recogí el mono y los guantes, y los apreté contra mi pecho; mis ojos se inundaron, y suspiré. 


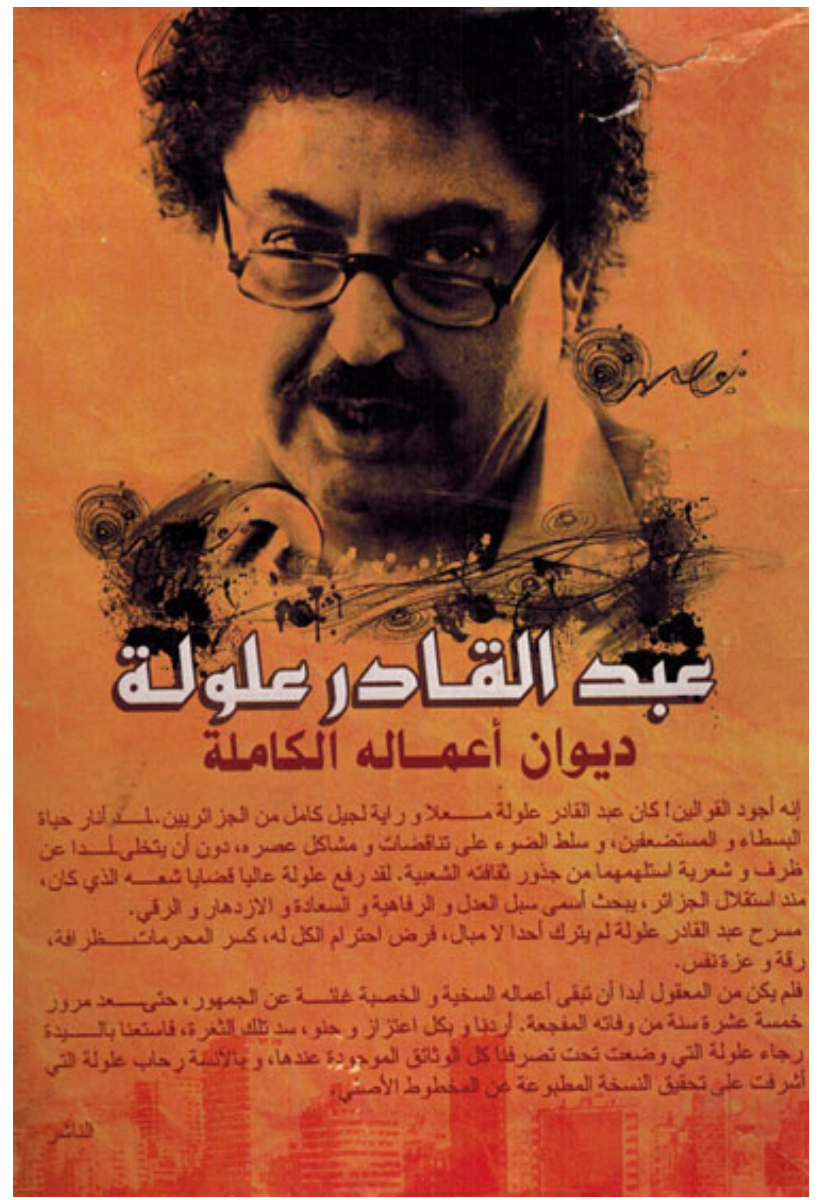

Contraportada del estuche de las obras completas de Abdelkader Alloula, Orán, Ministère de la Culture, 2009, 3 vols. 